\title{
Réplique au compte rendu d'Henri Goulet sur le livre Histoire du Mouvement Desjardins, tome 2 : La percée des caisses populaires, 1920-1944 (50,1, été 1996, 129-131).
}

\section{Pierre Poulin}

Volume 50, numéro 4, printemps 1997

URI : https://id.erudit.org/iderudit/305611ar

DOI : https://doi.org/10.7202/305611ar

Aller au sommaire du numéro

Éditeur(s)

Institut d'histoire de l'Amérique française

ISSN

0035-2357 (imprimé)

1492-1383 (numérique)

Découvrir la revue

Citer ce compte rendu

Poulin, P. (1997). Compte rendu de [Réplique au compte rendu d'Henri Goulet sur le livre Histoire du Mouvement Desjardins, tome $2:$ La percée des caisses populaires, 1920-1944 (50,1, été 1996, 129-131).] Revue d'histoire de l'Amérique française, 50(4), 631-632. https://doi.org/10.7202/305611ar d'utilisation que vous pouvez consulter en ligne. 
Réplique de Pierre Poulin au compte rendu d'Henri Goulet sur le livre Histoire du Mouvement Desjardins, tome 2: La percée des caisses populaires, 1920-1944 (50,1, été 1996, 129-131).

L'historien d'entreprise peut s'attendre à ce que la crédibilité de ses ouvrages soit mise en doute. Même s'il adopte une démarche scientifique et même s'il prétend travailler dans des cadres qui laissent place à la liberté intellectuelle, un fait demeure: l'entreprise l'a payé pour faire sa recherche. Dès lors, les soupçons sont permis. Il doit accepter cette règle du jeu, mais sans pour autant renoncer à un traitement objectif de la part de ceux qui recensent ses ouvrages.

Dans la recension du tome 2 de l'Histoire du Mouvement Desjardins (RHAF, 50,1, (été 1996): 129-131) Henri Goulet s'est montré vigilant afin de débusquer les éventuels pièges tendus par l'auteur et de retracer tout virus pouvant affecter l'étude. Les six premiers chapitres ont passé l'épreuve sans trop souffrir. Mais l'inévitable tare devait apparaître au chapitre 7: «Ici, écrit Henri Goulet, l'approche prend une tournure nettement plus hagiographique et cherche à justifier la pratique économique des caisses populaires axée davantage sur l'épargne que sur le crédit.» L'auteur de la recension espérait trouver dans cette section de l'ouvrage une analyse démontrant qu'au cours des années 1930 et 1940, les caisses n'auraient pas contribué au développement économique local. Selon Goulet, Ronald Rudin (In whose interest? Quebec's caisses populaires, 1900-1945, paru en 1990) «a démontré, de façon assez éloquente, que l'épargne accumulée dans les caisses populaires, contrairement à l'idée largement véhiculée, ne sert pas au développement économique local, mais se retrouve plus souvent qu'autrement, paresseusement, dans des obligations sécuritaires en dehors de la localité, chez les gouvernements provincial et fédéral, les municipalités et les commissions scolaires».

S'il avait lu Rudin avec un æil critique, il aurait pu tirer une conclusion plus nuancée. Bien sûr, Rudin souligne à gros trait le conservatisme de la gestion des caisses, mais il remarque aussi que les achats massifs d'obligations répondent en partie à des problèmes de liquidités excédentaires. Dans certaines paroisses, les fonds accumulés excèdent les besoins de crédit des membres. Ces fonds, il faut les employer quelque part pour qu'ils ne restent pas improductifs. Rudin écrit d'ailleurs à ce sujet: «Had Desjardins and his successors been less pragmatics the caisses would probably have collected large amounts of savings, earning nothing for the members.» (p. 72) Les obligations, qui sont généralement des valeurs sûres et facilement négociables, jouent un rôle nécessaire en assurant une proportion convenable de liquidité. Aucune institution financière ne peut prêter la totalité de son actif sans compromettre la sécurité des dépôts que lui confient ses épargnants. On peut accuser la propension de certaines caisses à placer trop d'argent dans les obligations, mais on doit aussi observer, comme le fait d'ailleurs Rudin, que, dans l'ensemble, les caisses achetaient proportionnellement moins d'obliga- 
tions que les banques ( $46 \%$ contre $57 \%$ en 1945) et consacraient une plus grande part de leur actif aux prêts personnels (p. 73).

Par ailleurs, les achats d'obligations ou les prêts consentis aux commissions scolaires ou aux municipalités n'étaient pas nécessairement contraires aux intérêts des membres ni à ceux du développement local. Les caisses cherchaient surtout à financer des institutions locales ou régionales et leur offraient souvent des conditions qu'elles n'auraient pu trouver ailleurs. Rudin écrit à ce sujet: «When credit was obtainable from other sources, the caisses invariably offered it at lower interest rate, in the process adding to the wealth of Quebecers.» (p. 72)

Enfin, les prêts aux membres des caisses populaires (personnels ou hypothécaires) représentaient tout de même plus du tiers de l'actif en 1945. Comment peut-on prétendre que les caisses n'auraient pas contribué au développement local tout en sachant qu'elles ne prêtaient généralement qu'à l'intérieur du cadre paroissial comme le voulaient leurs règlements? Si l'auteur de la recension a des doutes en particulier sur le soutien financier des caisses au développement des autres secteurs coopératifs, il existe de nombreuses études sur l'histoire des coopératives agricoles, des coopératives de pêche et d'habitation qui pourront l'éclairer sur le sujet.

Contrairement à ce que laisse entendre Goulet, je n'ai pas passé sous silence l'importance des fonds affectés aux placements et j'ai recensé les critiques adressées le plus fréquemment aux caisses à l'époque. J'ai cependant analysé le problème en tenant compte de la diversité des pratiques de prêts et de placements, très facilement observables dans les statistiques. Goulet, qui n'apprécie pas les nuances, n'y a vu qu'un agaçant «discours de justification». Mais qu'on le veuille ou non, la propension aux placements était particulièrement forte chez les grosses caisses urbaines les plus anciennes et cela, pour deux raisons: d'une part, parce que leur conseil d'administration était souvent dominé par des éléments de la petite bourgeoisie qui se montraient plus sensibles aux intérêts des épargnants qu'aux besoins des petits emprunteurs et, d'autre part, parce qu'elles avaient souvent d'importants surplus de liquidités. En milieu rural où l'on retrouvait près de $80 \%$ des caisses en 1945, les prêts retenaient une portion beaucoup plus grande de l'actif.

Quoi qu'il en soit, la structure de l'actif n'est pas, loin de là, le seul indicateur du rôle économique des caisses. On peut déplacer l'analyse du côté du profil des membres et des dirigeants, de la nature et des motifs des prêts consentis, des modalités de remboursement et des taux d'intérêt. On peut s'interroger sur la contribution des caisses du point de vue de la décentralisation économique, de l'accessibilité au crédit ou de l'éducation économique. Les réalités qui apparaîtront risquent fort de mener à des conclusions différentes de celles attendues par certain lecteur. 